\title{
ФИЛОСОФИЯ
}

\author{
UDC 1-165
}

\section{Language as Eigenform: Semiotics in the search of a meaning*}

\author{
D. E. Gasparyan
}

National Research University Higher School of Economics, 20, Myasnitskaya ul., Moscow, 101000, Russian Federation

For citation: Gasparyan D. E. Language as Eigenform: Semiotics in the search of a meaning. Vestnik of Saint Petersburg University. Philosophy and Conflict Studies, 2018, vol. 34, issue 4, pp. 474-492. https:// doi.org/10.21638/spbu17.2018.402

The problem of how signs acquire their meaning is characteristic of both the philosophy of language of the analytic tradition (Quine, Frege, Peirce, Wittgeinstein) and the continental one (Saussure, Hjelmslev, Jacobson, Bloomfield). At present, most scholars are inclined either to point out the priority of objects over the system of signs, or the system over the objects. However, neither version suggests a satisfactory solution.. On the one hand, we believe that the language and the world are external to each other and are independent from each other; but on the other hand, we cannot construct a model of language independent from the world (what does language denote, in that case?) and the world independent from the language (how is a world possible if it is not referenced?). This situation poses a problem. The Eigenform model can help shed light on it and suggests coherent solution; this model the possibility of overcoming the 'dilemma of preceding' (whether the language precedes the world or the world precedes the language). Similarly to the dilemma of observation (observer) and the world (whether observation (observer) precedes the world or vice versa), the Eigenform model shows that neither the signifier nor the signified precede the other, but rather intercondition each other. Thus, language creates the world of objects but is shaped by the world in turn. Unlike a similar language model developed by L. Wittgenstein, Eigenform model stipulates the principle of the world-language generation in a complex system of involved and/or mutual interpretations. The interpreter generates a meaning in the world, and in this process the interpreter himself is being formed as an interpretation (in particular, self-interpretation). Keywords: Eigenform, language, meaning, semiotics, semiosis, reference, self-reference, recursiveness, sign.

* The research has been performed within the grant of Russian Foundation for Basic Research № 18-011-00124 "Features of Phenomenology (phenomenological approach) in contemporary analytical philosophy of mind" (2018-2020).

(c) Санкт-Петербургский государственный университет, 2018 


\section{Introduction}

The metaphysics of Eigenform has a long history. In the philosophical context, Eigenform was first introduced within the framework of the concept of 'substance. Substance has a variety of interpretations in the history of philosophy. The closest concept to Eigenform's understanding is the idea of substance in Hegel (absolute as things in existence cognizing itself; [1] and Spinoza (causa sui - the reason for itself) [2]. In both structures, the point is the identity of the object and the subject - i.e. in essence, as it is understood in Eigenform. The main argument in favour of such a concept is the necessity of working with all-embracing formations - which, by definition, cannot have a meta-level. Spinoza was the first of the two to show that if we want to talk about the world in general (i.e. about the global system itself), one has to introduce the concept of substance. Substance can be one only as it embraces everything and by definition does not presuppose any meta-level dominating itself. Everything will then be its parts (attributes and modes). Such a substance creates the whole world, being the world itself - it thus creates itself from itself [3, p. 77]. As such, a substance cannot already have an external shape; due to its inclusiveness, it must be its own form or, to put it more correctly, we see an identity of form and content. In other words, a typical example of this form is at hand: $S(S)=S$, where $S$ is substance. If we imagine a singular world (substance, global system) as existing (Cc), but also knowing about its existence $\left(\mathrm{C}_{3}\right)$, this leads to following: $\mathrm{C} \downarrow \downarrow \mathrm{Cc}=\mathrm{Cc}$. And if substance-knowing is now interpreted mathematically as the function of substance (fC), and the substance-knowing itself $(\mathrm{Cc}$ ) as its argument (mathematical $\mathrm{x}$ ), we get the following formula: $\mathrm{fC} \downarrow \mathrm{x}=\mathrm{x}$, or in mathematical terms alone: $\mathrm{X}=\mathrm{f}(\mathrm{X})$. It is this formula named 'Eigenform' that acquired a dominant meaning in the modern calculation of forms.

The considered function is a special one: the identity of the form with the context is realized within it, which is absent in any other form. Conventional (non-proprietary) forms only reflect external objects and primary contents [4, p. 80]. But if the form is able to direct its secondary attention to the forms and modes (modus) themselves, then images pertaining to a higher (metaphysical) level appear, which are called metaphors. Finally, if all these metaphors remain part of a primary form, we are dealing with something containing its own form - Eigenform.

According to Foerster, Eigenform is a recursive form of description-construction (к) of something by a subject, which is description-construction ( $\mathrm{\kappa}$ ) of this very describingconstructing subject: $K=f(\kappa)[5, p .29]$. Kauffman, due to the recursion procedure, then implements the law of inversion of the form and content. Eigenform appears to be the form of the cognizing subject, and, in particular, a specific part - a subject operator capable of producing such contents, which immediately becomes forms: $x=f(x)[6, p .80]$. Finally, G. Spencer-Brown understands the form as a form of distinction (a form of differentiation). "We take, therefore, the form of distinction for the form" [7, p.7]. The form is content or meaning, which arises as a result of distinction. Together with the content itself, conditions are given providing for the form of distinction - which is exactly what Spencer-Brown studied. Spencer-Brown's model of Eigenform is as follows: Eigenform is a form capable of producing meanings which are its own content-rich law-conditions of existence: $\mathrm{y}=\mathrm{f}(\mathrm{y})$.

Summarizing these three options of defining Eigenform, I take the following formulation as the starting point of my research: Eigenform is a characteristic mode that pro- 
duces non-Eigenforms and contents with the help of the same form acting simultaneously as its own forms. The most important characteristics of Eigenform for this research are its capacity for differentiation (not directly attached to the subject) and the concept of meaning. I therefore follow Spencer-Brown's approach. The graphic representation of SpencerBrown's model of Eigenform corresponds, to a large extent, to the famous image of hands painting each other [8]. Another good illustration might be a sheet of paper, represented by two of its sides, which in their inextricability forms the integrity of the sheet [9, p. 69].

As we see, the idea of Eigenform is closely connected to the concepts of recursion and self-referentiality (direction at oneself). Foerster himself placed emphasis on human cognition (I, the observer) as an embodied Eigenform [8, p. 30]. Thus, we see a so-called 'looped', 'self-oriented', recursive type of knowledge, where reflection on the knowledge would be smoothly integrated into the subject of the knowledge itself [10, p.55-57]. Eigenform allows for expressing the nature of various sorts of finite things quite productively - in essence, for all those that do not envisage meta-language as an attempt to construct a meta-description, there will be a contradiction.

In particular, such a form, as I will try to show in this article, is language. I understand that in the development of Eigenform, one can feel the desire for a certain universal calculation. Participants in this trend seek a certain proto-language of forms with the simplest and maximally plastic alphabet and syntax [11, p.69]. This gives me additional grounds on which to connect Eigenform with language.

Correspondingly, my hypothesis is that language is one more finite form, the 'external' description of which is impossible. It follows that the application of second-order cybernetics to Eigenform might be adequate. In this article, I would like to concentrate on one relatively small aspect of the idea of Eigenform suggested by Foerster, namely, that neither observer nor the thing observed can precede each other, but instead mutually assume each other. In my research, language would stand in place of the observer, and in place of the thing - the world itself. To specify further, I focus on the problem of noting, and in particular, on how signs correspond to things. Therefore, I will try to show that the sign and the object (the signifier and the signified) do not precede one another and do not exist isolated from each other, but, on the contrary, condition each other. Thus, language creates the world of objects, but in turn, it is created by the world. Therefore, it is a model of self-referentiality which arranges the form of language as Eigenform as the idea of 'mutual referentiality', as we see it in the relation between language and the world.

We will mostly talk about language as a linguistic phenomenon here, nevertheless, we will underline that the problem of the correlation between signs and things is not to be understood too broadly. The sign is not supposed to be strictly linguistic, but any sign that performs the function of designation. The sign as a typically broad concept is studied in semiotics. Semiotics is a scientific discipline that studies the production, structure and functioning of different sign systems as well as storing and transferring information. Semiotics assumes that any cultural phenomena - starting from ordinary comprehension and ending with the art and science - are reinforced in signs and present certain sign mechanisms. In the field of vision of semiotics, there will be natural and artificial languages, all types of visual sign systems, various systems of signaling in the nature and society. As far as the natural language in semiotic theory is concerned, it acts, on the one hand, as 'interpretant of all other semiotic systems' [12, p.71], but at the same time, appears to be a certain case of 'semiotic function' [13, p.54]. 
The question of relating signs to things presents a difficulty. There exist many theories explaining how this happens, however, in practice practically none are free from contradictions. The supposition that in many aspects this relation is connected with ontology underlies this research. This is a dual ontology, according to which, there is reality external to observation, which might be described and formalized in signs. In such ontology, the observer and the thing observed do not need each other for their existence [14, p. 96]. The Eigenform model suggests revising this ontology, which will help to construct a more coherent theory of notion. As we will see, there is a more profound philosophical problem at the root of this model based on relation between language and reality. If it is possible to revise the traditional dual ontology, where language and reality exist independently from each other, then it may also be possible to explain how language manages to 'capture' reality. It is in this sense that the application of the Eigenform model could be extremely productive.

\section{The problem of meaning}

In reality, several problems of meaning exist at once. In particular, the problem of how signs acquire their meanings is a longstanding problem both in the analytic tradition (Quine, Frege, Peirce, Wittgenstein), and the continental one (Saussure, Hjelmslev, Jacobson, Bloomfield). Philosophers of the analytic tradition mostly engage with the problem of whether this meaning testifies to the integrity of certain characteristics or whether the meaning is only an arbitrary reference to a specific object. The central problem here is to define what sets up the identity of the signified object, in spite of any changes in its characteristic features [15, p. 77]. On what ground do we attach signs to a thing, or, in other words, how do we describe the supposedly non-linguistic reality with the help of language?

According to a more recent version of the symbol-grounding problem, it is related to the problem of how words (symbols) get their meaning, and hence, to the problem of what meaning itself really is $[15$, p. 46-50]. How are those symbols (e.g., the words in our heads) connected to the things to which they refer? It cannot be through the mediation of an external interpreter's head, because that would lead to an infinite regress, just as looking up the meanings of words in a - unilingual) dictionary of a language that one does not understand would lead to an infinite regress.

Finally, according to some positions, language passively reflects the world, while, according to others, it actively forms it (Sapir, Wharf). The underlying concept of the second position is linguistic relativity stating that cognitive processes might be under the influence of those categories and patterns that are offered to a person by language. Some philosophers are inclined to understand cognizing as a form of inner speech, inborn or acquired in the process of mastering the language. In this context, the problem of relation between language, knowledge, and the external world is discussed as well the notion of truth. Some philosophers (Putnam, Fodor, Davidson, Dennett) see the problem in the following way: language gives names to what already exists in the objective world, and as a result, this categorization is not variable, but is pre-defined to a certain degree. Other philosophers (Wittgenstein, Quine, Searle, Foucault) believe that categorization and conceptualization are learnt and at their base are subordinated to chance; that objects in the world might be classified in a variety of ways, which gives rise to a variety of different forms of description and understanding of the same phenomenon. Philosophers also hold views regarding the question of whether language is predominantly an instrument for de- 
scription and references of already existing objects in the world or whether it is a system that creates objects $[16, \mathrm{p} .68]$.

The key question uniting all these approaches is that of whether objects precede notion (their capturing in signs) or whether the process of notion itself (the system of signs) shapes the objects of 'the external world'? The common feature of many theories that justify meaning, including that of Harnad, is the understanding of the justification (veracity) of such an action as notion. The action can be justified (comprehended), and this will be the action that is causally effective - the processed information must have certain means of influencing the external world [15, p.90]. If the system of notation is isolated from the environment and is causally closed, it inevitably fails to meet the conditions of causative effectiveness. Accordingly, to create the theory of a meaning, in which the meaning and reasons for actions are justified, the existence of the external world needs to be postulated with necessity.

Thus, at present, the majority of theories are inclined to point out the priority of objects over the system of signs. They, therefore, rest upon the traditional referential theory of meaning, which presupposes the presence of the external world - the sign has a meaning when it refers to a certain object outside the system of signs. This theory is a classical theory of sign and meaning, descended from Aristotle's theory of the sign. According to him, the meaning of a certain concept is a real thing (for example, the meaning of the word 'tree' is a real tree), to which we can point (ostensibly) and thus establish the meaning. However, first, such an interpretation does not explain how complex abstract notions are assigned a meaning (for example, 'universe' or 'reality') [17, p. 78]. And it does not explain why different languages categorize the world in different ways (as we see when we have problems translating from one language into another). This problem is connected with another one. If we think that the signified (thing) precedes the notion, then we cannot explain how the thing is formed as an object. In order for the thing (for example, 'a tree') to be recognized as a certain object, language has to be already applied $[18$, p. 341-358].

To sum up, it is possible to say that by considering language and the world as external to each other and independent from each other, we cannot build a model of language independent from the world and the world independent from language (how is a certain world possible if it is not signified in any way?). Below we will consider how the principle of recursiveness can be introduced into the field of notion, and how it will help to change the correlation between the sign and the thing.

\section{Language is the form arranged by internal differences}

Let us show how language is arranged as a system. Later, we will see that this is not simply a system, but a system that shapes the Eigenform. In order to do so, let us first consider the principle of differentiation, which might be also called the principle of de-substantivation. This principle directly leads to the fundamental concepts of Spencer-Brown and his famous work Laws of Form [19, p. 69]. Here he argues that the basis of any formal calculation there is a primary operation of 'differentiation'. We come across the very same principle within the framework of Saussure's structural linguistics [9, p. 183]. This principle is important in that it shows how objects behave inside such systems, which are all-embracing and total, i.e. in essence they are self-forms or Eigenform. 
If we are to use the operator's symbols, then to express the meaning of the operator itself, the symbolic equation might be written as $\mathrm{O}(\mathrm{A})=\mathrm{B}$, where $\mathrm{O}$ - operator as opposed to the subject-observer, $\mathrm{A}$ - argument on which the operator acts, $\mathrm{B}$ - the value received after the action of $\mathrm{O}$ onto A. In this case, the idea of objects as symbols of Eigenforms as the operators of notion can be expressed very easily - as the search for the meaning of argument A, on which the operator forms so-called fixed points, i.e. the equation is performed in relation to the Eigenforms of the operator: $\mathrm{O}(\mathrm{A})=\mathrm{A}$. Objects are such fixed points of the operators' reflections [14, p. 76].

16. The principle of differentiation or de-substantivation lies in the fact that in spite of the classical conception that an object is not a thing - something that can be pointed to - objects are not essences or substances in the classical sense. In order to understand the essence of this principle, we can ask: what defines the meaning of an object? In fact, there are two ways of answering the question 'What is a table?'. The first is to point the finger to a certain closest table with the words 'this is the table". The second is to give a definition of 'table, whereby it would be such that the person asking would undoubtedly recognize 'table' when they saw one. The first method cannot be considered satisfactory since to point to a specific 'table' does not necessarily mean pointing at the essence of 'table. When asking about the meaning of a certain object, we are interested in a definition that might be used as a collective term to identify all other samples of one essence. This means we must describe it or characterize the essence. This can be only done by means of language, as we have to talk about the table as a concept. Now asking about the meaning of the table, we have to ask about the meaning of the concept 'table.' And then we will have to sort out how meaning in language is shaped and distributed.

In order to answer this question, let us fix the process of notion in the language at its simplest level. In particular, let us find out what shapes the meaning of the most minimal element of the language - the phoneme (letter). Take the letter 'A'. We can ask: what is the essence of the letter 'A'? We must not be confused by the simplicity of this object - if the object exists, it should have an essence. We understand very well that the letter 'A' might be written in ink on paper or in chalk on a board, that it might be written in blue, but also in red, that it might take different shapes in being written, such as this or that 'A'; however in all these cases we will recognize it as the same letter ' $\mathrm{A}$ ', and not as an array of different objects. For example, Turing tests aim at distinguishing computer robots from people, and work through the writing of symbols (letters or digits): a person can identify the object but the computer fails [20, p. 12].

So, what is the essence of the letter 'A' if neither the shape nor the color or conditions of writing or pronunciation - as an acoustic object, the letter ' $\mathrm{A}$ ' can also be pronounced briefly or with a singing accent, quietly or loudly, in a male or a female voice, etc.) deal with this issue? Linguistics gives the following answer: the meaning of a phoneme is defined by its place in the system. This place is the same as function, the mode of usage, or the possibility of replacement with another phoneme from the given system of phonemes. The letter ' $\mathrm{A}$ ' is no more than the possibility of being any other letter from the array of letters in a particular alphabet. The fact that the letter ' $\mathrm{A}$ ' is not either the letter ' $\mathrm{B}$ ' or the letter ' $\mathrm{S}$ ' is what constitutes its essence. Saussure states in this respect: "the differences distinguish one sign from all the others that constitute a system" [9, p.47]. Let us note once again: the sign does not have anything material (essential, substantial) that would differentiate it from the 'essence' of another sign. The difference is not content-related but concerns the 
formal principle - the sign 'A' is a sign 'A' because it is not the sign ' $\mathrm{B}$ ' ('S'.... 'Y'). Thus, the 'essence' of the sign is its difference from others, which, in essence, is what creates this sign as a separate sign.

Now let us come back to the initial example of the table. According to the considered principle of differentiation or de-substantivization, we should assume that the concept 'table' has its meaning not due to certain qualitative characteristics peculiar to it, but due to the fact that 'table' as a concept is opposed to all other items in the vocabulary of this particular language. Thus, concepts are also purely differential and "are defined not by their positive content but negatively by their relations with the other terms of the system" [21, p. 184]. In spite of being counter-intuitive, to a certain degree, this view maintains that the meaning of the sign depends only on whether this sign appears in those places where other signs might be used. For example, in the sentence 'He ran up the hill', 'climbed', 'drove' or 'flew might be used, and it is due to this that this word 'ran' has a meaning. Compare this with 'It is a long way ... go'. Here the gap can only be filled with the particle 'to'. It is for this reason that 'to' means nothing in this context. On this reading, a concept merely exists somewhere and waits to be given the name; but if this were so, words in different languages would be strictly identical, which is not exactly so.

Thus, according to the principle of differentiation or de-substantivization, one should refuse the rhetoric of substantiality as applied to signs. Such a methodology, "firstly denies treating parts of relation as independent entities; on the contrary accepts as a basis for its analysis the relations between them; and secondly, [...] introduces the concept of a system, relying upon its 'self-closeness"' [12, p. 171]. Signs are not the same entities as the objects of the physical world. Their existence is not substantial, but strictly 'referential' or 'differential'. They form a system taken together, which has a particular form, arranging the location of its parts-signs in such a way that each of them has a meaning. If we are to understand the form broadly in this case - as some uncertainty appearing in connection with the architecture of inner distinctions, given in the single space of our perceptions, then we see that the definition of a system used in cybernetics is of second order.

\section{The principle of differentiation and objects as tokens}

The model of differentiation and de-substantivization is based on two important principles which allow for considering objects as tokens, according to the model of the object given by Foerster.

The first principle concerns the fact that our sensorial perception of reality is not defined by the senses, but by the system of signs forming this perception. We usually think that in order to perceive a sound, we need to hear it with the help of our ears. Thus, a sound might be presented as a certain acoustically perceived substance. However, one simple experiment disproves this. As linguists testify: if two speakers of different language-families hear two words, e.g. 'ten' and 'tan', only the native speaker will notice the difference in the sounds in the language in which the sounds 'e' and 'a' perform a sound-differentiating function, i.e., simply speaking, participate in the phonetic structure of the language. Recognition - the so-called phonemic hearing) of certain sounds works only if it allows for differentiating between the words; other differences are inconsiderable to the hearing. Thus, unlike the classical understanding of the sensual image, where perception is described in a substantianalist way, linguistics brings in an important addition - native speakers 
of a language perceive only that sensual reality which differentially participates in the arrangement of the language they understand. Language as 'a bundle of differentiated values' thus shapes the potential of our perception.

It is obvious that this principle correlates with the principle of Eigenform, according to which the stable entities of our world, which we are accustomed to calling 'objects' (tables, trees, houses, etc.), present the results of the operators of supervision. Here Foester offers an analogy with the structure of quantum physics, where observed values appear in connection with the projections of the system, as consequences of the configuration of inner operators [5, p.77]. This would correspond to what is stipulated by the system of notion.

The second principle is also based on the fact that objects are tokens, but lies in the bilateral theory of the sign, sometimes called non-classical or the non-Aristotelian theory of meaning. Its designation also involves, to a considerable degree, eliminating objects-inthemselves from the procedure of notion in general and the structure of the sign, in particular. Let us consider this principle in more detail. The classical representation, following Aristotle, considers signs and their meaning, e.g. the name of the object, for example, the word 'tree' (written or pronounced), and its meaning - here a physical tree growing outside the window. It was thought that the sign existed in itself, and the thing existed separately; however, signs can be attached to things and represent them [22, p. 78]. Likewise, it was thought that the meaning of a sign was a real physical object in the material world. The structural linguistics rejects this in favor of a theory of the unity of two sides, one of which is called signifier, and the other signified ('signifier', however, means that the 'signified' is being identified). Here the sign does not refer to the meaning (of the thing) outside, it refers to meaning in its own boundaries. The meaning turns out to be a derivative of the sign, although it is found in the world as something external. Such a mechanism of notion is obviously subordinated to the logic of Eigenform, where 'objects' as tokens are formed inside but are projected 'outside', which in turn allows for shaping a meaning. Thus, the whole construction has a cyclical structure of 'self-formation'.

Saussure justified the dual nature of the sign in the following way. The sign cannot be thought of as something autonomous, as it always already means something, such that it has to stay in indissoluble connection with its meaning. But meanings are not physical objects existing somewhere in the world independently from signs. Consequently, the 'sign' includes both the 'signifier' and 'the 'signified' within itself and mutually holds them in a referential procedure of notion. This model can be represented as follows:

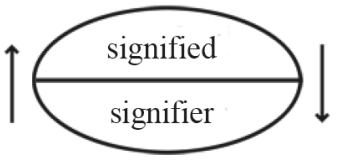

Why is the 'signified' (i.e. meaning) not a thing? Is the meaning of the word 'tree' not a real tree, as the classical theory of meaning teaches us? In spite of the credibility of this idea, it is not. This is impossible, first of all, because a specific physical object cannot be part of the sign, and we have said that the signified should be part of the sign. Secondly, when we say a 'tree', our thought deals with the concept of the tree, i.e. with the ideal tree and not a real one. Therefore, the 'signified' is not a thing. 
In turn, the 'signifier' is also ideal. Suppose we write the word 'tree' in ink on paper or on the board. Will the 'signifier' be the aggregate of all the drops of ink or particles of chalk? No, because everything that is perceived by our sense organs will always be the psychic correlate of the material object - the written or pronounced word 'tree'. The 'signifier' presents itself as an 'acoustic image' that should be differentiated from the directly material sounding. The signifier is the psychic correlate of the sounding. Therefore, the acoustic image might be called a 'material' element only as an ideal representation or a sensory impression. Within the boundaries of the comprehended speech, the sign cannot consist of a sound without a meaning or of a meaning without a sound. Thus, the signifier is not a sequence of soundings, making up the name (e.g. the sound sequence 'table'), studied by phonetics and registered with the help of electromagnetic devices, but is the image of this sound sequence. Therefore, the 'signifier' is also ideal $[9$, p. 83].

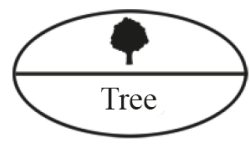

The constancy of the sign is provided by its ideality. As the objects of the physical world are distinct, there are no two absolutely identical things. Similarly, we also pronounce words differently (with a different tune, tone, and volume), as well as we write them differently (in different handwriting, in block letters or hand-written, in ink or graphite, on paper or in sand, etc.); however the sign itself is unchangeable since it is ideal. If the signified were a real physical object (and thus always changeable) and not a concept, then the sign and in consequence language would be impossible.

Thus, the signified assumes a relation to the concept and not to the thing; not the object itself but an idea about an object. Such a definition leads to a change in our understanding of the nature of the signified, which for traditional representations of language was nothing but an analogue of a thing, a physical object. The structural model of the sign dematerializes the signified as it excludes reference to the objects existing in the world. For example, when a speaker says 'table' and a listener understands them, nowhere in the field of vision of the interlocutors does there appear a real physical table. The signified is the image of a thing born in mind and related to other similar images [20, p.12].

Thus, the sign is arranged so that the ideal acoustic image refers to the same ideal concept, whereas the question of supporting this scheme through the presence of the real material world remains open. Hence, the meaning is kind of 'sewn' into the sign and not located outside the sign. This might seem strange - are there no real trees in the world which we can approach and touch, and which are material and not ideal? Are they not those referents/meanings in the end to which the signs refer? In spite of the intuition of realism, we should reason differently here: the tree that we approach and touch will become a 'tree' for us, a particular object and not the pile of meaningless pixels; but language is responsible for shaping an object. Thus, when we stroke the 'tree' along its 'trunk', admiring its 'crown', we are motivated by the dictionary (and not by immediate sensuality, only which provides access to the pixels), which allows us to see a tree in the object, and nothing else [23, p. 551]. 


\section{How the world is correlated with the language: The identity of the thing and the sign}

The considerations above regarding the problem of the correlation between the language and the world, it seems, were not radical enough in one sense - that is, in pointing out that the pre-existence of the signified to the signifier is not obvious. It is not quite clear whether reality precedes the sign or the sign precedes reality; and if the latter is true, should we just announce that the sign is an (extra-linguistic) reality? Let us consider these questions in order.

As it was said above, a linguistic sign is not the connection between a real (physical) thing and its name, but the unity of concept (signified) and the acoustic image (signifier). But if the linguistic sign is immaterial, this definition of a sign will immediately create a fundamental difficulty: if the 'body' of the sign is absolutely ideal, what is the relation of the sign to physical things? Does this mean that things can be neglected, and that we do not need the real world to establish meaning? It cannot be so. Common sense tells us that beyond the sign there are things, and although the inner structure of language does not require things, the sign relates to things in an external way. In order not to contradict common sense, we need to complement the ideal sign, or more correctly, the sign surrounded by things,. But do these things have to be present in order for the sign to perform its function, or can it do without them? As we have mentioned, the sign functions when only two sides are represented, namely, the signified and the signifier, both of which are ideal. Consequently, the relation of the sign to a material object seems to be rather problematic.

Why should a thing be added to the sign if the sign is not connected to it by any genetic ties? One possible answer suggested by linguistics is as follows. The existing complex system of language might function without referring to the real world of things; however, the initial formation of language should have been performed in connection with things. In other words, underlying the 'sensible' idea of the sign is such a ground: at the stage of its appearance each sign was related to a real thing; however, language then became autonomous and was no longer in need of the intermediary services of things. Such an explanation, built on the logic of a 'first time', seems somewhat mythical as it does not explain how 'the first' signified was a thing but then stopped being one, etc. Philosophers $[7 ; 24]$ paid much attention to this difficulty, pointing out that the concept of the sign does not stipulate a mechanism of interaction with external objects satisfactorily. This difficulty stems from a linear representation of the sign and its meaning - there is a certain starting point at which the sign was fixed to the thing. Anticipating things, we will say that in case of applying the Eigenform model, one does not need to introduce a 'first time' - in the circularity of the system, signs are always related to each other but in such a way that a meaning 'arises' [25, p. 96-99].

If now we involve the second substantial definition of the sign and stay within the limits of a specific language, as a purely differential formation, we will have to say that, first of all, signs are related to each other by not disposing of any of their substantial characteristics, i.e. not by having any sovereign significance beyond the boundaries of the system as a whole. A paradoxical but quite logical conclusion follows from this regarding the impossibility of the existence of a single sign. A language with one sign is not possible, which serves as good confirmation of the principle of radical differentiality (non-substantiality) of the sign and language. If a sign appears, there must be at least one more somewhere, 
providing the notional thingness of the first, and vice versa. In other words, it is impossible to create a language that would be represented by one sign as a second sign is always necessary, which by differentiating would define the meaning of the first $[26, \mathrm{p} .76]$. In turn, both the signifier and the signified are exclusively co-related objects. These two sides of the sign are also only retained by the mutually-referential connection, i.e. one exists only by referring to the other, which means that neither the signifier nor the signified precede the other. The principal fusion between the signified and the signifier is substantial, as the first exists only concerning and in connection with the latter, and vice versa.

At this point two new ideas begin to shape. As the signified and the signifier refer to each other, the signified, in the first place, cannot be isolated (removed from the structure of the language and be put outside), and secondly, it is impossible to define what precedes what - the signified before the signifier, or vice versa. If we accept this structure of the sign, we should agree that there are no relations of precedence whatsoever between them - they exist at the same time, concerning and in relation to one another, i.e. whenever there is one (the signifier), there is always another (the signified). In this sense, the Eigenform works well - form does not precede content, and content does not precede form: they form and create each other. Within the boundaries of the sign itself, the structure of productive circularity comes into action [3]. This might seem counter-intuitive since common sense insists that the signified has the priority of primordiality and exists before the signifier. However, here we need to ignore the data of ordinary presentation and see that the signifier and the signified are held by each other; they can have neither a conceptual nor objective advance. This again shows us the relation to the Eigenform model, where we are accustomed to calling 'objects' (tables, trees, houses etc.) Foerster suggested that they are understood as the results of the operators of the system, making comparisons with the structures of quantum mechanics, where observed values appear in relation to the conditions of observing [27, p. 60].

This model has something in common with the theory of the language offered by Wittgenstein. According to him, the only reality of speech is propositions (sentences), and the only reality of the world is facts [28, p.21]. Facts are not the same as sentences, though they have the same form. To illustrate this, we can again think of a sheet with two sides. 'It is raining' is simultaneously a fact and a proposition describing the fact. Using the apparatus of Eigenform to understand this structure, it is possible that 'It is raining' is a sentence that describes the fact that 'it is raining', which is constructed by the sentence 'it is raining', which describes the fact 'it is raining. This structure presupposes an infinite regress, according to Kaufmann's model (if $\mathrm{OA}=\mathrm{A}$, then in place of $\mathrm{A}$, one can put $\mathrm{OA}$, getting: $\mathrm{OOA}=\mathrm{A}$. One can continue like this endlessly, gaining: $\mathrm{OO} \ldots \mathrm{OOA}=\mathrm{A}$ ), but we will not consider this in detail here.

The last problem regarding the question of the correlation between the language and reality is the so-called principle of the arbitrariness of the sign. According to this principle, there is no natural or necessary connection between the signifier and the signified. The connection between them is established quite arbitrarily — any signifier can denote any signified. There are no genetic or any other causative-consecutive preconditions for which sound combination ('c-a-t') will refer to the concept ('cat'); a concept might be represented by any other signifier. Thus, the "the process which selects one particular sound-sequence to correspond to one particular idea is completely arbitrary" [9, p. 111]. Linguists argue about the arbitrary or non-arbitrary character of the correlation between the signifier and 
the signified as two sides of the sign, but also about the arbitrariness or non-arbitrariness of the relation between the sign and the object or phenomenon, external in relation to the language or the world - to a hypothetic extra-linguistic reality. In other words, the principle of arbitrariness is attributed not only to the sign but also to the whole system of signs.

If words corresponded to objects, it would be possible to establish precise equivalents for words in different languages. But anyone who speaks more than one language knows perfectly well how difficult it is to find equivalent concepts in the languages. The equivalents often bear a conditional and compromised character, assuming that the context will be lost during the translation from one language into another. This happens because each language shares a reality through arbitrary linguistic categories, and the world of our common ideas, shaped by the 'native' language, might be differentiated in a different way. In fact, there are no such two languages which categorize the reality in an identical way. A particular language shapes a particular world.

How the world correlates with the language: The recursion of signified notions

In view of the above, we come to an unexpected conclusion: 'language is in no way related to the world, which can be complemented with an even more paradoxical assumption: 'however, the world is connected to language. Language or the whole procedure of notion might be represented in this case as the standard Eigenform model: the signified world (Mo), which is also the existing world (Mc), will be formalized as follows: Mo $\downarrow \mathrm{Mc}=$ Mo. The world is always the signified world (and in fact shaped by signification), and language always already signifies (particularly) this world. We live in the world that is structured and categorized by signs. World = Signified world. This formula is read in the other direction as well: the Signified world is the World in which we live; it is the only world, which we know and assume to be ultimately real.

It should be understood that signs do not possess a magical ability to 'create' firm tables, sweet fruit, or wet water. Signs do not create the physics of the world. However, they create the meanings of things which we solely and always deal with. To use a language means to deal with concepts and not directly with things. Correspondingly, to speak or think always means to deal with the meanings of current developments and not something happening by itself. We grasp only what we provide with meaning ourselves. Meanings are always set up by the language. However, in this model the necessity of dividing the world into 'the world in itself' and 'the world given to us in signs' is lost. Depending on what language 'tells' us, the world will be produced for us as a certain 'reality' signified in advance. The model of language as Eigenform defines that language does not 'fix' reality but rather 'constitutes' it. It is the signs that form what we can see. However, prior to the procedure of notion, there are no signs themselves - they always have to mean something in order to be signs. Such is the world as Eigenform. In this world, the form is also content, since how things are done - with the help of signs) is what we cognize with the help of the same signs. The sign (of Reality) = Sign or Meaning (of Reality)= Meaning: S $(R)=S$. The language 'first' creates the world and then recognizes it. It is possible to say that it creates it in the first cycle of notation and recognizes it in the second. However, this sequence is meaningful and not chronological. These two stages are always synchronized in time.

Using one of the literal meanings of recursion it is possible to say that the procedure of notion is itself a recursive formation. If we are given a certain sentence, the meaning of this sentence will be another sentence, which, in turn, will require another one to clarify its meaning, ad infinitum. In order for something meaningful to be uttered, it should be 
formulated in the shape of a sentence consisting of words to be understood, for which we would need to formulate some sentences disclosing their meaning. In doing so, we have to introduce new words demanding explication in new sentences, and so on and so forth. If we accept a sentence defining a certain name, it is clear that each name denoting an object can itself become the object of a new name, denoting its meaning: $\mathrm{n} 1$ refers to $\mathrm{n} 2$; $\mathrm{n} 2$ refers to $\mathrm{n} 3$, and so on. When we utter something, we never enunciate the immediate sense of what our point is about. The meaning of what we are talking about might be conveyed, if at all, by the object of the following sentence, the meaning of which is not conveyed either. In such a situation a kind of endless multiplication occurs [17]. This partially accords with the model of Kaufmann's 'signifying shift', in which he develops the idea of a situation when the name becomes an equal part together with the object in the composition of a certain single integrity [29, p. 93]. In this model the endless composition of the operator of a meta-name is the form of the operator of denotation itself [30, p.99-101]. This is an example of the semiotic model of Eigenform.

Native speakers of a language master the meanings of words thanks to the fact that they use the same linguistic apparatus ${ }^{1}$ - with language representing a closed system, differentiated according to the principle of mutual references [31]. Based on these assumptions, one might abandon realistic interpretations of meaning. Meaning will thus be formed by the systematicity of language (the inner procedure and the distribution of elements), and not the relation of a sign to the 'real' thing. It is this principle that allows us to bring language closer to the Eigenform and to see its objects as tokens.

We can thereby draw the conclusion that it is not possible to talk about objects as certain 'things in themselves' lying outside the space of notion. Objects have no sense whatsoever without the preliminary background of sign-operators and can only arise in the substantial sign-medium, represented as a system of operators of notion [32]. 'Inner things' also arise in the form of such forms as possessed by the operators of notion - our thoughts, feelings, conditions of consciousness and, last, our own 'I'. It is possible for the operators themselves to be also represented as invariants of some other operators [14]. The ability of arguments to become operators, and vice versa, is also one of the characteristic peculiarities of the 'Eigenform calculation'.

Thus, the basic difference that the language sets up is that between the world and language. Spencer-Brown depicts signs as an angle which has a line on one side (boundary), and is empty on the other side (along the boundary). It is not important what marks what, whether boundary marks emptiness or emptiness marks boundary; the form is born in this mutual referentiality. It is also not important whether the world limits language or language limits the world; this limitation in itself is performed inside language. However, due to this differentiation, the world in fact appears. This statement can be drawn out of the first axiom given by Spencer-Brown: "We take as given the idea of a distinction and the idea of indication, and that it is possible to make an indication without drawing a distinction" [33, p. 69]. The point is about the trivial idea that any indication of something implies a procedure of its differentiation from something else. However, in the case considered

${ }^{1}$ This accords with what Piaget says about how consciousness performs its first differentiation with the help of the language. Considering the ontogenesis of a human being, he writes: "Through language, grammar, and syntax, he learns a particular description of the world which he will be taught to call reality" [20, p. 28]. 
here, the indication of the world demanding differentiation from language is performed inside language itself.

Any indication, of course, is a reference to something external to language. At the same time, this indication might be performed exclusively within the framework of the system of notion (language) and only by means of this system. In the world in itself, differences between a tree compared to a 'tree' do not exist. This differentiation between the inner 'apple' and the external apple are generated by the system itself and correspondingly inside it, for all that the tree is understood as part of the external world [34]. Notwithstanding its 'external' character, this 'object' still remains part (or another side) of the differentiation, the creator of which is the system of notation itself (language). In this sense, the external world belongs to the system as part of a differentiation generated by the system itself.

50. Such a model is possible because the 'signified' to which the 'signifier' refers acts as a 'signifier' itself, i.e. in order to have a meaning it should have the status of addressing. Any "signified is also in the position of a signifier" [35, p. 37]. In the system of the language, where only immanent connections are given, all relations are maintained by the movement of mutual references. However, the 'signified' exists because there is a movement of a referential network of signs. The 'signified' as a specific effect is peculiar to the notation itself as it is built into the replacing system of the language, which has been mentioned above. In this system, each element possesses meaning because it can be replaced by another. However, in such a movement of notation, retention in a constant, identical state is impossible since the condition for having a meaning serves as its 'displacement', that is, its representation via another sign [5, p. 120]. This brings it closer to Kaufmann's 'signifying shift', as each name - sign) can always be used repeatedly under the guise of the signified.

It is here that the most important principle of recursion becomes essential for maintaining the Eigenform. Mutual referentiality does not simply involve going around in a circle, such that the signified and the signifier remain the same. It occurs according to the recursion model - with a multiplication of references, where each new sign takes the place of the signified in a new cycle of notation. Graphically it might be depicted as follows:

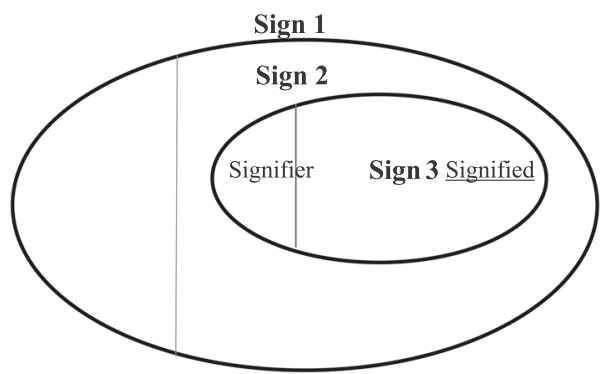

But is it not possible to reach a finite number of steps in notation, come out towards the world and point at the thing itself? Is it not possible to point at a real dog, for example, as something that founds and gives true grounds for a sign? However, on the one hand, to say so is to introduce an unjustified abundance into the system of notation - even if there were no dog in the world, we would be able to talk about it. However diligently we appeal to the thingness, bringing together language and reality, we risk missing each other 
at their closest point. Their crossing is unattainable; as soon as the thing is named - 'This is a dog' - we find ourselves in the system of language. In order to understand, we should follow from one concept to another, subordinated to language's differentiation. But left unnamed, 'the dog' would simply not exist - there might be something else, but not the 'dog') [36, p. 67-68].

In general, and on the whole in semiotics (whether in Saussure or Peirce), reality is considered as thought and accessible solely in the form of signs. Peirce introduces the concept of reiteration (the analogue of Spencer-Brown's condensation) [37], where the appearance of reality is a reiteration or processing of used signs (tokens). Barthes radicalizes this approach, insisting on the fact that signs have no referents whatsoever [21]. The sign itself - simply due to the fact that it is the unity of two sides, the signifier and the signified - cannot have an external side, and indeed does not have any external referents in the sense suggested by Barthes. One can pay attention to the signified or the signifier, but this differentiation itself cannot have any contradictions, or in other words, the external referent of this differentiation will be an uncertain space (see the second axiom of SpencerBrown, where uncertain space turns out to be the consequence of the delimitation (marking) of the boundary itself or the differentiation of the differentiation). In this sense, one can talk about the endless approaching of the 'thing', which is always deposited [35]. Even if certain things are beyond the boundaries of language, we can but endlessly approach them, producing ever new and new iterations and reiterations. This is how the Eigenform reveals itself: it pre-sets its internal, as well as external; however, in spite of this pure simulativity, such a fold generates a productive ontology [7]. It turns out to be 'alive'. As a result of such self-arrangement, the world knows about itself. The world arranges itself in language, which is the world. Or the world generates language, which generates the world, which can be read backwards - language generates the world, which generates language. Hence we get the Uroboros image - the best illustration of the Eigenform. In this context, this means that whilst language shapes the world, language itself appears in this world as belonging to the world and in this sense not forming a meta-reality.

When we bracket the 'real' or 'extra linguistic' dimension, the signifier might have the unrestricted freedom of notation. Unrestricted by the imperatives of a reference, it is possible to communicate. The major part of these communications will be communications about communications, as Luhmann states [38]. It is only possible to attribute meaning to an object inside the structure of difference, i.e. within the boundaries conditioned by the system itself. The signified is then an 'object' that constitutes the notion itself by means of an indication of the 'external world'. One is able to talk about this world only when running an internal circle of notation, 'making a loop'. Each circle of this loop is a certain meaningful communication (from micro- to macro-formations), which constitute reality in integrity - always meaningful in language.

\section{Conclusion}

The points made here agree with those made by Foerster: we are unable to know what reality is beyond language. In a certain sense, I have also tried to show that the question of 'reality external to the language' can be eliminated due to its being unproductive and basically pointless. We are by nature the inventors of ourselves; we construct our reality and our meaningful surroundings, which is principally always already ours. There is noth- 
ing 'external' to language, or, more correctly, the external of language is the other side of the internal.

Signs make systems of communications possible, as well as systems of consciousness due to the fact they make self-separation, self-isolation, and closure of the said systems possible, where their separation from the rest of the world is understood as the second external side of the sign [19, p.87-94]. It is true that this cognitive world, inaccessible to the stated systems, might be comprehended as a form of chaos, as the place where differentiations and boundaries have not been made as yet - as 'wild' when it comes to our understanding of primitive societies, like a transcendental god or noumenal world when it comes to philosophy; and it might be even considered a primary singularity in modern scientific interpretations. But all things considered, this world cannot serve as a referent of communicatory signs.

Thus, language is our own Eigenform par excellence. A constant recursion creates an always-arranged world of experience, where the signifier and the signified make up an inseparable unity. According to Foester, everything said is said by the observer (as there is no observation without an observer). Descriptions are always self-descriptions. We applied this model to language, defining the stance taken by the language to the world.

Underlying this model is the problem of meaning, and in particular, the problem of how signs acquire their meaning. As we have seen, in order for a thing (e.g., 'tree') to be recognized as a subject, we need to apply language (the system of observation-notation). We cannot say that the language and the world are independent from each other. On the contrary, if we consider them to be mutually referential, we can offer a more coherent model. The principle of the relation between the signified and the signifier will help with this. We can therefore maintain: 1 . The ideal (inner-language nature of the signified) and 2. The differentiated (inner-language) nature of any procedure of notation. Everything that happens in the process of notation happens inside language. However, this 'inside' also has its 'external side' - the world itself, which is meaningful to the degree to which it appears to be notified. Its form is a whole and is represented by two sides - signs and things, sentences and facts, which cyclically or mutually referentially create and support each other.

Thus, language is the Eigenform in a philosophical sense - it creates the world in itself and through itself. The signified mutually and referentially refers to the signifier, graphically reminding us of Escher's hands or two sides of a sheet of paper. However, their mutual referentiality does not simply form a circle, where the signified and the signifier remain the same. It forms a model of recursion - a multiplication of references, where each sign appears to be in the place of the signified in the new cycle. Strictly speaking, as a result of such a scheme, the world must appear, which, if we look closely, is always the result of notation-comprehension. The world = the signified world.

\section{References}

1. Haken, H. (1977), Synergetics, Springer-Verlag, Berlin, Germany.

2. Spinoza, B. (2002), "Ethics", in and ed. by Morgan, Michael L. (ed.), Spinoza: Complete Works, transl. by Shirley, S., Hackett, Indianapolis, IN.

3. Füllsack, M. (2014), "The circular conditions of second-order science sporadically illustrated with agent-based experiments at the roots of observation", Constructivist Foundations, vol. 10, no. 1, pp. 46-54.

4. Bredin, H. (1984), "Sign and Value in Saussure", Philosophy, vol. 59, no. 227, pp. 66-77. 
5. Erickson, M. J. (2000), Truth or Consequences, IVP, Downers Grove, IL.

6. Kauffman, S. (2003), "Eigenforms - Objects as Tokens for Eigenbehaviors", Cybernetics and Human Knowing, vol. 10, no. 3-4, pp. 73-90.

7. Deleuze, G. (1969), Logique du sens, Les éditions de Minuit (coll.“Critiqu”), Paris, France.

8. Escher, M. C. (1989), Escher on Escher: Exploring the Infinite, Harry N. Abrams, New York, NY.

9. Saussure, F. de (1983), Course in General Linguistics (trans. Roy Harris), Duckworth, London, UK.

10. Maturana, H.; Varela, F. (1987), The Tree of Knowledge, New Science Library, Boston, MA.

11. Kauffman, S. (2005), "Eigenform, Kybernetes", The International Journalof Systems and Cybernetics, vol. 34, no. 1/2, pp. 129-150.

12. Benveniste, E. (1971), Problems in general linguistics, in 2 vols., transl. by Mary Elizabeth Meek, University of Miami, Coral Gables, Fl.

13. Piaget, J. (1977), The Grasp of Consciousness: Action and concept in the young child, Routledge Kegan Paul, London, UK.

14. Kampis, G. (1991), Self-Modifying Systems in Biology and Cognitive Science, Oxford, New York, Pergamon Press.

15. Gasparyan, D. (2015), "What can the global observer know?', Constructivist Foundations, vol. 10, no. 2, pp. 300-310.

16. Carnap, R. (1956), Meaning and Necessity: a Study in Semantics and Modal Logic, University of Chicago Press, Chicago, IL.

17. Russell, B. (1905), “On Denoting”, Mind, New Series, vol. 14, no. 56, pp. 479-493.

18. Rocha, L. M. (1996 b), "Eigenbehavior and symbols", Systems Research, vol. 12, no. 3, pp. 371-384.

19. Umerez, J. (1995), "Semantic Closure: A guiding notion to ground Artificial Life", in Moran, F., Moreno, A., Merelo, J.\#J. and Chacon, P. (eds.), Advances in Artificial Life, Springer Verlag, Berlin, Heidelberg, Germany, pp. 77-94.

20. Piaget, J. (1954), The construction of reality in the child, Basic Books, New York, NY.

21. Barthes, R. (1966), "Introduction à l'analyse structurale des récits", Communications, no. 8, pp. 7-33.

22. Hegel, G. W. F. (1977), Phenomenology of spirit, transl. by A. V. Miller with analysis of the text and foreword by J. N. Findlay, Clarendon Press, Oxford, UK.

23. Foerster, H. (1977), "Objects: tokens for (eigen-)behaviors", in Inhelder, B., Gracia, R. and Voneche, J. (eds.), Hommage a Jean Piaget: Epistemologie Genetique et Equilibration, Delachaux et Niestel; Neuchâtel, France.

24. Chomsky, N. (1968), Language and mind, Harcourt, Brace \& World, New York, NY.

25. Rosch, E. (1978), "Principles of Categorization", in Rosch, E. and Lloyd B.\#B. (eds.), Cognition and Categorization, Lawrence Erlbaum Associates, Hillsdale, NJ.

26. Wilber, K. (1996), The Atman Project: A Transpersonal View of Human Development, Quest Books, Wheaton, IL.

27. Foerster, FI. (1960), "On self-organizing systems and their environments", in Yovits, M.\#C. and Cameron, S. (eds.), Self-Organizing Systems, Pergamon Press, NY, pp. 31-50.

28. Wittgenstein, L. (1921), "Logisch-Philosophische Abhandlung", Annalen der Naturphilosophie, vol. 14, pp. 185-262.

29. Kauffman, S. (1993), The Origins of Order: Self-Organization and Selection in Evolution, Oxford University Press, Oxford, UK.

30. McCall, S. (1999), "Can a Turing Machine Know that the Gödel Sentence is True?", Journal of Philosophy, vol. 96, no. 10, pp. 525-532.

31. Pattee, H. H. (1995), "Evolving self-reference: matter, symbols, and semantic closure, Communication and Cognition", Artificial Intelligence, vol. 12, no. 1-2, pp. 9-27.

32. Neumann, J. (1966), The Theory of Self-Reproducing Automata, University of Illinois Press, Champaign, IL.

33. Spencer, Brown G. (1969), Laws of form. Allen and Unwin, London, UK.

34. Medina-Martins, Pedro R.; Rocha, L. (1992), "The in and the out: an evolutionary approach", in Trappl, R. (ed.), Cybernetics and Systems Research '82, World Scientific Press, pp. 681-689.

35. Derrida, J. (1967), L'Écriture et la différence, Seuil, Paris, France.

36. McDorman, K. F. (2007), "Life after the symbol system metaphor", Interaction Studies, vol. 8, no. 1, pp. $143-158$

37. Peirce, Ch. S. (1955), "Logic as Semiotic: The Theory of Signs (1898)", in Bucher, J. (ed.), Philosophical Writings of Peirce, Dover, New York, NY, pp. 98-119. 
38. Luhmann, N. (1990), Essays on self-reference, Columbia University Press, New York, NY.Received: March 16, 2018 Accepted: June 26, 2018

Author's information:

Gasparyan Diana E. — PhD, Associate Professor; anaid6@yandex.ru

\section{Язык как Eigenform: семиотика в поисках значения}

\section{Д. Э. Гаспарян}

Национальный исследовательский университет «Высшая школа экономики», Российская Федерация, 101000, Москва, ул. Мясницкая, 20

Для цитирования: Gasparyan D.E. Language as Eigenform: Semiotics in the search of a meaning // Вестник Санкт-Петербургского университета. Философия и конфликтология. 2018. Т. 34. Вып. 4. С. 474-492. https://doi.org/10.21638/spbu17.2018.402

Проблема того, как знаки обретают свое значение, является традиционной проблемой философии языка как в аналитической традиции (Куйан, Фреге, Пирс, Витгенштейн), так и в континентальной (Соссюр, Ельмслев, Якобсон, Блумфилд). Ключевой вопрос, объединяющий все эти подходы: предшествует ли мир предметов означению (схватыванию их в знаках) или сам процесс означения (система знаков) формируют объекты «внешнего мира»? На сегодняшний день большинство решений склонно указывать на приоритет либо объектов перед системой знаков, либо системы знаков перед объектами. Однако и та и другая версия не вполне удовлетворительно справляется с решением задачи. С одной стороны, мы считаем, что язык и мир являются внешними друг для друга и независимыми друг от друга, но, с другой стороны, мы не можем построить модель независимого от мира языка (что язык тогда означает?) и независимого от языка мира (как возможен определенный мир, если никак не означен?). Эта ситуация представляет собой проблему. Пролить свет на данную проблему и предложить наиболее когерентное ее решение может помочь модель Eigenform (собственной формы), которая показывает, как можно преодолеть «дилемму предшествования» (языка миру или мира языку). По аналогии с дилеммой предшествования наблюдения (наблюдателя) миру или мира наблюдению (наблюдателю) миру модель Eigenform должна показать, что ни означение, ни означаемое не предшествуют друг другу, но взаимообусловливают друг друга. В отличие от сходной модели языка, разработанной Л. Витгенштейном, модель Eigenform позволяет оговорить принцип порождения языка миром и мира языком в процессе сложной системы вложенных и/или взаимных интерпретаций. Интерпретатор формирует значение в мире, но и сам при этом формируется как интерпретация (в частности, самоинтерпретация).

Ключевые слова: Eigenform, собственная форма, несобственная форма, язык, значение, семиотика, семиозис, референция, самореференция, рекурсия, знак.

Контактная информация:

Гаспарян Диана Эдиковна - канд. филос. наук, доц.; anaid6@yandex.ru 